\title{
Modal Analysis of a Simply Supported Steel Beam with Cracks under Temperature Load
}

\author{
Yijiang Ma, ${ }^{1}$ Guoping Chen, ${ }^{2}$ and Fan Yang ${ }^{1}$ \\ ${ }^{1}$ School of Naval Architecture and Ocean Engineering, Jiangsu University of Science and Technology, Zhenjiang 212003, China \\ ${ }^{2}$ State Key Laboratory of Mechanics and Control for Mechanical Structures, Nanjing University of Aeronautics and Astronautics, \\ Nanjing 210016, China
}

Correspondence should be addressed to Yijiang Ma; yima@nuaa.edu.cn

Received 27 March 2017; Revised 8 August 2017; Accepted 14 September 2017; Published 3 December 2017

Academic Editor: Yuri S. Karinski

Copyright (C) 2017 Yijiang Ma et al. This is an open access article distributed under the Creative Commons Attribution License, which permits unrestricted use, distribution, and reproduction in any medium, provided the original work is properly cited.

\begin{abstract}
Based on the transfer matrix method, an analytical method is proposed to conduct the modal analysis of the simply supported steel beam with multiple transverse open cracks under different temperatures. The open cracks are replaced with torsion springs without mass, and local flexibility caused by each crack can be derived; the temperature module is introduced by the mechanical properties variation of the structural material, and the temperature load is caused by the temperature variation, which can be transformed to the axial force on the cross-section. The transfer matrix of the whole beam with the temperature and geometric parameters of cracks can be obtained. According to boundary conditions of the simply supported beam, natural frequencies of the beam can be calculated, which are compared with the finite element results. Results indicate that the analytical method proposed has a high accuracy; the natural frequencies of the simply supported steel beam are mostly affected by the temperature load, which cannot be ignored.
\end{abstract}

\section{Introduction}

Because of the high strength, good mechanical properties and recyclable, the alloy steel structures have been more and more widely used in engineering practice in recent years. However, the steel material has a fatal weakness, which is the weaker high temperature resistance, and the mechanical properties of the alloy steel are very sensitive to the temperature variation. The influence of the temperature variation on the dynamic characteristics of the structure is mainly in the following three forms: (1) temperature variation makes the size of the structure change; (2) temperature variation makes the temperature load generated within the structure; (3) temperature variation makes the mechanical properties of materials change. In the high temperature environment, the mechanical properties of the alloy steel have a great degree of deterioration, and the ultimate bearing capacity of the structure will be reached in a relatively short time, which will threaten the safety of the structure seriously. So, it has a really high engineering value to investigate the dynamic characteristics of the alloy steel structure under different temperatures.
Mesquita et al. [1] studied the critical temperatures of lateral unrestrained steel beams under high temperatures. Huang and Tan [2] used the Rankine approach to analyse the high temperature resistance of steel columns, and the accuracy and feasibility of this approach were verified by experiments. Based on the interval modelling of uncertainties, Pi et al. [3] estimated the variation of the materials properties and geometry of the beam under a linear temperature gradient and investigated the thermal-elastic responses of the elastically restrained steel beams. Heidarpour and Bradford [4] developed a novel numerical method to investigate the nonlinear vibration of a restrained steel beam under high temperature, and the finite element model was established by ABAQUS to demonstrate the accuracy of the method proposed. Several references [5-7] analysed the dynamic responses of the steel beams under high temperatures and different loads. Mahi et al. [8] derived the governing equations of motion by Hamilton's principle and proposed an exact solution to investigate the free vibration of the beams with different boundary conditions in the temperature field. 
Literatures above investigated the influence of the high temperature on the dynamic characteristics of beams and columns and concluded that high temperature seriously weakened the mechanical properties of the structure. But these literatures neglected the influence of the temperature load and structural damage, which could not describe the working situation of the structures objectively.

In the application of engineering, structures working in high temperature and vibration environment are prone to appear varying degrees of structural damage, and structural damage occurs mostly in the form of cracks. The existence of cracks will damage the strength of the structure and reduce the safety and reliability of the structure. So, the dynamic analysis of the cracked structure under high temperature has been concerned by the scholars. Wang et al. [9] investigated the variation of each order natural frequency of a simply supported beam with only one crack under high temperature, but the temperature load caused by the temperature variation was not considered. Based on the transfer matrix method, $\mathrm{Ma}$ and Chen [10] calculated the natural frequencies of the variable cross-section beam with multiple cracks under different temperatures, and the accuracy of this method was verified by the finite element method. Considering the influence of the temperature variation, Karličić et al. [11] developed analytical model to investigate the free vibration of the cracked nanoscale beams. Literatures above discussed the influence of the high temperature on the natural frequency of the cracked beam, without consideration of the temperature load generated by the temperature variation. For the simply supported beam, the length and shape of the cross-section do not change with the temperature variation, but the axial temperature load is generated on the cross-section of the beam, so the effect of the temperature load cannot be ignored.

In this paper, a special simply supported beam is assumed, which is that the horizontal directions of the left and right ends of the simply supported beam are fixed. Considering the temperature load generated on the cross-section, the modal analysis of a steel beam with multiple transverse open cracks is conducted under different temperatures. The torsion springs without mass are used to replace the transverse cracks on the beam, and the damage degrees of transverse cracks on the beam are described by the local flexibility. At the same time, the temperature load is transformed into the axial force at the cross-section of the simply supported steel beam, and the transfer matrix of the whole beam is derived. According to the boundary conditions of the simply supported beam, the natural frequencies of the beam with multiple transverse open cracks can be calculated under different temperatures.

\section{Establishment of the Model}

As shown in Figure 1, the research object of this paper is a special simply supported alloy steel beam with $n$ transverse open cracks (the horizontal displacements of the left and right ends of the simply supported beam are zero, and the transverse cracks always keep open during beam vibration), homogeneous and isotropic. The geometric parameters of the beam are as follows: $L$ is the length of the beam; $b$ is the

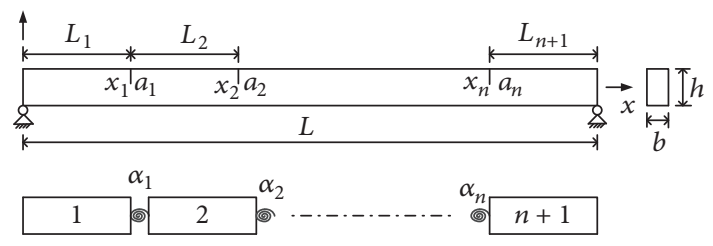

FIGURE 1: Model of the simply supported steel beam with multiple cracks.

width of the beam; $h$ is the height of the beam; the position of each transverse crack on the beam is $x_{i}$; the depth of each transverse crack is $a_{i}(i=1,2, \ldots, n)$. In this paper, the reference temperature is $0^{\circ} \mathrm{C}$.

According to the virtual work principle, Dimarogonas and Paipetis [12] derived the formula of the local flexibility caused by each transverse crack on the beam. The local flexibility of each crack can be expressed in the following form:

$$
\alpha_{i, T}=\frac{6 \pi\left(1-v_{T}^{2}\right) h}{E_{T} I} f\left(r_{i}\right),
$$

where $\alpha_{i, T}$ is the local flexibility caused by each crack under different temperatures; $T$ is the temperature; $E_{T}$ is the elastic modulus of the alloy steel under different temperatures; $\nu_{T}$ is Poisson's ratio of the alloy steel under different temperatures; $I$ is the moment of inertia of the cross-section; $r_{i}=a_{i} / h$ is the relative depth of each crack; $f\left(r_{i}\right)$ is the local flexibility function corresponding to each crack, and [12] gives an expression as follows:

$$
\begin{aligned}
f\left(r_{i}\right)= & 0.6272 r_{i}{ }^{2}-1.04533 r_{i}{ }^{3}+4.5948 r_{i}{ }^{4}-9.973 r_{i}{ }^{5} \\
& +20.2948 r_{i}{ }^{6}-33.0357 r_{i}{ }^{7}+47.1063 r_{i}{ }^{8} \\
& -40.7556 r_{i}{ }^{9}+19.6 r_{i}{ }^{10} .
\end{aligned}
$$

The thermal expansion happens to the beam as the temperature rises, and the temperature load is generated on the cross-section of the simply supported beam due to the deformation constraints, which can be transformed into the axial force $N_{T}$. Based on the theory of Material Mechanics, the expression of the axial force at the cross-section of the beam is shown as follows:

$$
N_{T}=E_{T} A \alpha_{T} T,
$$

where $A$ is the area of the cross-section; $\alpha_{T}$ is the thermal expansion coefficient of the alloy steel; [13] gives the function expression of the thermal expansion coefficient of the alloy steel under different temperatures:

$$
\alpha_{T}=(11+0.062 T) \times 10^{-6} \mathrm{~m} / \mathrm{m} \cdot{ }^{\circ} \mathrm{C},
$$

where the temperature $T \in\left[0,600^{\circ} \mathrm{C}\right]$.

Each transverse open crack is considered as the breakpoint of the whole beam, and the cracked beam can be separated into $n+1$ intact beams by $n$ cracks, which are connected by $n$ torsion springs without mass. The length of 
each intact beam is $L_{i}(i=1,2, \ldots, n+1)$. Assume that each intact beam is the Euler-Bernoulli beam, and the differential equation of the transverse vibration of the beam under axial force in [14] is as follows:

$$
\rho_{T} A \frac{\partial^{2} w_{i}}{\partial t^{2}}+N_{T} \frac{\partial^{2} w_{i}}{\partial x_{i}^{2}}+E_{T} I \frac{\partial^{4} w_{i}}{\partial x_{i}^{4}}=0
$$

where $x_{i} \in\left[0, L_{i}\right] ; \rho_{T}$ is the density of the alloy steel under different temperatures.

Equation (5) is the four-order linear differential equation with constant coefficients, which can be solved by the separation of variables. Assume that each intact beam has the following form of the modal function:

$$
w_{i}\left(x_{i}, t\right)=W_{i}\left(x_{i}\right) q_{i}(t)
$$

Substituting (6) into (5), the following equations can be obtained:

$$
\begin{aligned}
E_{T} I W_{i}^{(4)}\left(x_{i}\right)+N_{T} W_{i}^{\prime \prime}\left(x_{i}\right)-\rho_{T} A \omega_{T}^{2} W_{i}\left(x_{i}\right) & =0, \\
q_{i}^{\prime \prime}+\omega_{T}^{2} q_{i} & =0 .
\end{aligned}
$$

Assuming that $\delta=\sqrt{N_{T} / E_{T} I}$ and $\beta^{4}=\omega_{T}^{2}\left(\rho_{T} A / E_{T} I\right)$, solution of (7) can be written as

$$
\begin{aligned}
W_{i}\left(x_{i}\right)= & c_{i 1} \cos s_{1} x_{i}+c_{i 2} \sin s_{1} x_{i}+c_{i 3} \cosh s_{2} x_{i} \\
& +c_{i 4} \sinh s_{2} x_{i},
\end{aligned}
$$

where $s_{1}$ and $s_{2}$ are the natural vibration parameters of the beam subjected to the axial force, $s_{1}=\sqrt{\delta^{2} / 2+\sqrt{\delta^{4} / 4+\beta^{4}}}$ and $s_{2}=\sqrt{-\delta^{2} / 2+\sqrt{\delta^{4} / 4+\beta^{4}}}$.

\section{Transfer Matrix Method}

According to the theory of Material Mechanics, each state vector (the angle of deflection $\theta$, the bending moment $M$, and the shearing force $Q$ ) at the cross-section of the EulerBernoulli beam has the following expression:

$$
\begin{gathered}
\theta=\frac{\mathrm{d} W}{\mathrm{~d} x}, \\
M=E_{T} I \frac{\mathrm{d}^{2} W}{\mathrm{~d} x^{2}}, \\
Q=E_{T} I \frac{\mathrm{d}^{3} W}{\mathrm{~d} x^{3}} .
\end{gathered}
$$

The state vectors of the cross-section of the steel beam are adopted to define an array of mechanics
$K_{i}=\left[\begin{array}{llll}W_{i} & \theta_{i} & M_{i} & Q_{i}\end{array}\right]^{T}$. For the left side of each intact beam, the array of mechanics can be obtained as follows:

$$
\begin{aligned}
W_{i}(0) & =c_{i 1}+c_{i 3}, \\
\theta_{i}(0) & =c_{i 2} s_{1}+c_{i 4} s_{2}, \\
M_{i}(0) & =-s_{1}{ }^{2} E_{T} I c_{i 1}+s_{2}{ }^{2} E_{T} I c_{i 3}, \\
Q_{i}(0) & =-s_{1}{ }^{3} E_{T} I c_{i 2}+s_{2}{ }^{3} E_{T} I c_{i 4} .
\end{aligned}
$$

The equation group (10) is changed into the matrix form:

$$
K_{i}(0)=\left[\begin{array}{c}
W_{i}(0) \\
\theta_{i}(0) \\
M_{i}(0) \\
Q_{i}(0)
\end{array}\right]=R_{i}\left[\begin{array}{c}
c_{i 1} \\
c_{i 2} \\
c_{i 3} \\
c_{i 4}
\end{array}\right],
$$

where

$$
R_{i}=\left[\begin{array}{cccc}
1 & 0 & 1 & 0 \\
0 & s_{1} & 0 & s_{2} \\
-s_{1}{ }^{2} E_{T} I & 0 & s_{2}{ }^{2} E_{T} I & 0 \\
0 & -s_{1}{ }^{3} E_{T} I & 0 & s_{2}{ }^{3} E_{T} I
\end{array}\right] .
$$

For the right side of each intact beam, the array of mechanics can be obtained as follows:

$$
\begin{aligned}
W_{i}\left(L_{i}\right)= & c_{i 1} \cos s_{1} L_{i}+c_{i 2} \sin s_{1} L_{i}+c_{i 3} \cosh s_{2} L_{i} \\
& +c_{i 4} \sinh s_{2} L_{i}, \\
\theta_{i}\left(L_{i}\right)= & -c_{i 1} s_{1} \sin s_{1} L_{i}+c_{i 2} s_{1} \cos s_{1} L_{i} \\
& +c_{i 3} s_{2} \sinh s_{2} L_{i}+c_{i 4} s_{2} \cosh s_{2} L_{i}, \\
M_{i}\left(L_{i}\right)= & -c_{i 1} s_{1}{ }^{2} E_{T} I \cos s_{1} L_{i}-c_{i 2} s_{1}{ }^{2} E_{T} I \sin s_{1} L_{i} \\
& +c_{i 3} s_{2}{ }^{2} E_{T} I \cosh s_{2} L_{i} \\
& +c_{i 4} s_{2}{ }^{2} E_{T} I \sinh s_{2} L_{i}, \\
Q_{i}\left(L_{i}\right)= & c_{i 1} s_{1}{ }^{3} E_{T} I \sin s_{1} L_{i}-c_{i 2} s_{1}{ }^{3} E_{T} I \cos s_{1} L_{i} \\
& +c_{i 3} s_{2}{ }^{3} E_{T} I \sinh s_{2} L_{i} \\
& +c_{i 4} s_{2}{ }^{3} E_{T} I \cosh s_{2} L_{i} .
\end{aligned}
$$

Similarly, the equation group (13) is changed into the matrix form:

$$
K_{i}\left(L_{i}\right)=\left[\begin{array}{c}
W_{i}\left(L_{i}\right) \\
\theta_{i}\left(L_{i}\right) \\
M_{i}\left(L_{i}\right) \\
Q_{i}\left(L_{i}\right)
\end{array}\right]=S_{i}\left[\begin{array}{c}
c_{i 1} \\
c_{i 2} \\
c_{i 3} \\
c_{i 4}
\end{array}\right],
$$

where 


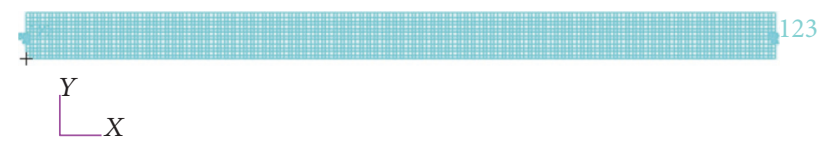

FIGURE 2: 3D mesh model of the simply supported cracked beam.

$$
S_{i}=\left[\begin{array}{cccc}
\cos s_{1} L_{i} & \sin s_{1} L_{i} & \cosh s_{2} L_{i} & \sinh s_{2} L_{i} \\
-s_{1} \sin s_{1} L_{i} & s_{1} \cos s_{1} L_{i} & s_{2} \sinh s_{2} L_{i} & s_{2} \cosh s_{2} L_{i} \\
-s_{1}{ }^{2} E_{T} I \cos s_{1} L_{i} & -s_{1}{ }^{2} E_{T} I \sin s_{1} L_{i} & s_{2}{ }^{2} E_{T} I \cosh s_{2} L_{i} & s_{2}{ }^{2} E_{T} I \sinh s_{2} L_{i} \\
s_{1}{ }^{3} E_{T} I \sin s_{1} L_{i} & -s_{1}{ }^{3} E_{T} I \cos s_{1} L_{i} & s_{2}{ }^{3} E_{T} I \sinh s_{2} L_{i} & s_{2}{ }^{3} E_{T} I \cosh s_{2} L_{i}
\end{array}\right]
$$

Substitution of (11) into (14) yields the state vectors equation of each intact beam:

$$
K_{i}\left(L_{i}\right)=S_{i} R_{i}^{-1} K_{i}(0),
$$

where $S_{i} R_{i}^{-1}$ is the transfer matrix of each intact beam.

When the whole cracked beam is subjected to the axial force, [15] gives the transfer equation of the left and right surfaces of the crack at the location of each transverse crack:

$$
\left[\begin{array}{c}
U_{i+1}(0) \\
\theta_{i+1}(0) \\
M_{i+1}(0) \\
Q_{i+1}(0)
\end{array}\right]=T_{i}\left[\begin{array}{c}
U_{i}\left(L_{i}\right) \\
\theta_{i}\left(L_{i}\right) \\
M_{i}\left(L_{i}\right) \\
Q_{i}\left(L_{i}\right)
\end{array}\right]
$$

where $T_{i}$ is the transfer matrix of each transverse crack and $T_{i}=\left[\begin{array}{cccc}1 & 0 & 0 & 0 \\ 0 & 1 & \alpha_{i} & 0 \\ 0 & 0 & 1 & 0 \\ 0 & 0 & -2 \delta^{2} \alpha_{i, T} & 1\end{array}\right]$.

Therefore, for the beam with $n$ transverse cracks, the transfer equation of the whole cracked beam can be obtained as follows:

$$
\left[\begin{array}{c}
W_{n+1}\left(L_{n+1}\right) \\
\theta_{n+1}\left(L_{n+1}\right) \\
M_{n+1}\left(L_{n+1}\right) \\
Q_{n+1}\left(L_{n+1}\right)
\end{array}\right]=H\left[\begin{array}{c}
W_{1}(0) \\
\theta_{1}(0) \\
M_{1}(0) \\
Q_{1}(0)
\end{array}\right]
$$

where $H=\left(S_{n+1} R_{n+1}{ }^{-1}\right) T_{n} \cdots\left(S_{2} R_{2}{ }^{-1}\right) T_{1}\left(S_{1} R_{1}{ }^{-1}\right)$ is the transfer matrix of the whole cracked beam.

In the state vectors of the left and right ends of the simply supported beam, the deflection and bending moment are usually equal to zero:

$$
\begin{aligned}
U_{1}(0) & =0, \\
U_{n+1}\left(L_{n+1}\right) & =0 \\
M_{1}(0) & =0, \\
M_{n+1}\left(L_{n+1}\right) & =0 .
\end{aligned}
$$

So, a $2 \times 2$ characteristic matrix $H_{S S}$ can be derived from the transfer matrix of the whole cracked beam, and the natural frequencies of the simply supported cracked beam can be calculated by the following formula:

$$
\operatorname{det} H_{S S}=0 \text {, }
$$

where $H_{S S}=\left[\begin{array}{ll}H_{12} & H_{14} \\ H_{32} & H_{34}\end{array}\right]$ is the characteristic matrix of the simply supported beam.

The natural mode corresponding to each order natural frequency of the whole cracked beam can be obtained through (8).

\section{Finite Element Method}

In this paper, the finite element software Patran is used to establish the geometric and mesh model of the simply supported cracked steel beam. In the finite element modelling of the cracked beam, the three-dimensional entity elements are adopted. A node is set at the crack tip of the transverse crack, and both surfaces of the crack are the surfaces of the three-dimensional entity elements, then the meshes of the crack surfaces are disconnected and discontinuous. The temperature load can be described by the axial force of the cross-section, which is generated by the temperature variation.

The natural frequencies of the cracked simply supported beam can be calculated by the finite element analysis software Nastran. Compare the natural frequencies obtained by the analytical method proposed in this paper with the finite element results, and the accuracy of the proposed method can be demonstrated. It is assumed that there is only one transverse open crack on the simply supported steel beam, and the geometric parameters of the crack are as follows: $x_{1} / L \in$ $[0,1], a_{1} / h=0.3$; the temperature $T=100^{\circ} \mathrm{C}$. As shown in Figure 2, the 3D mesh model of the simply supported beam with a transverse crack is established according to the boundary conditions of the special simply supported beam.

\section{Results and Discussions}

As shown in Figure 1, the geometric parameters of the simply supported steel beam are as follows: $L=1 \mathrm{~m}, h=0.06 \mathrm{~m}$, 


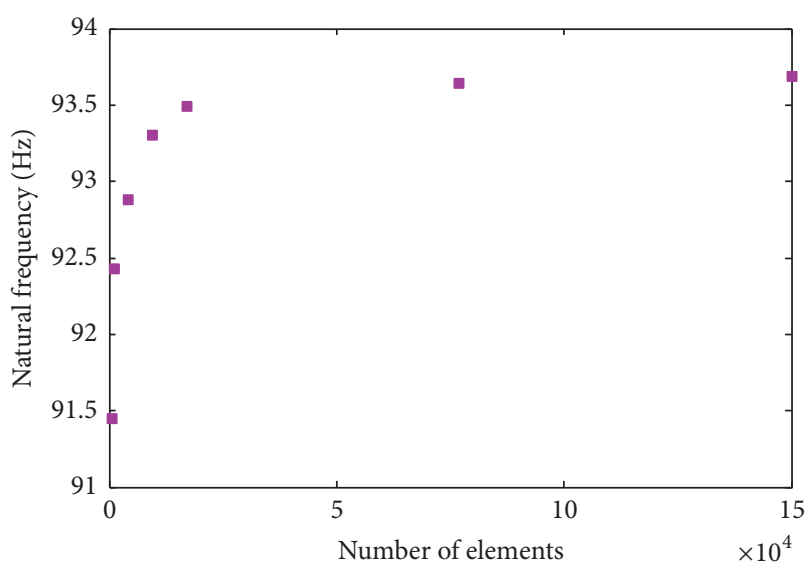

- First-order natural frequency

(a) First-order natural frequency

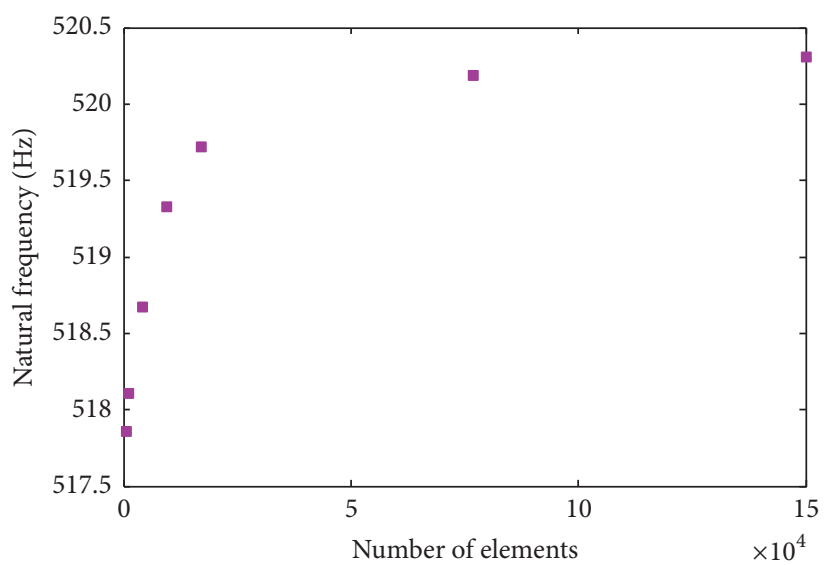

- Second-order natural frequency

(b) Second-order natural frequency

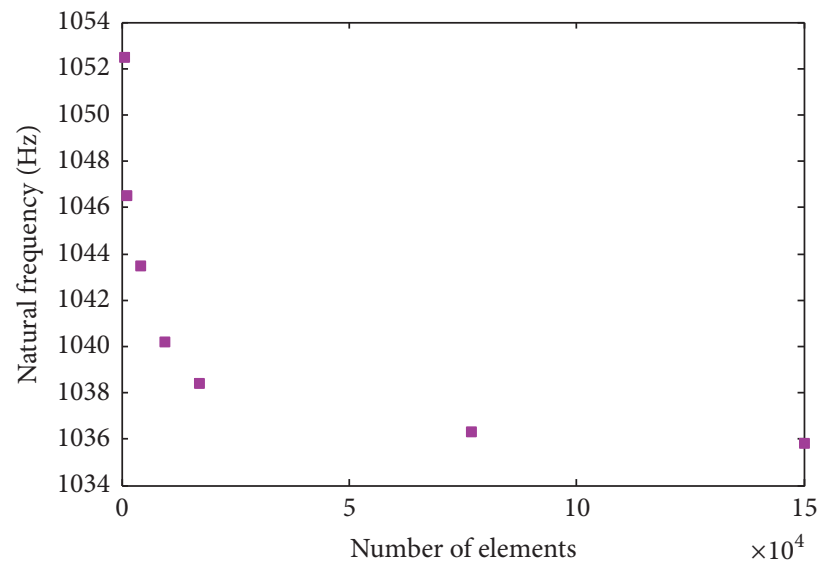

- Third-order natural frequency

(c) Third-order natural frequency

FIGURE 3: Convergence of first three-order natural frequencies of the cracked beam.

$b=0.02 \mathrm{~m}$; the material of the beam is the low carbon alloy steel AISI1050 [16], and the mechanical parameters of the material at room temperature are as follows: $E_{20^{\circ} \mathrm{C}}=$ $210 \mathrm{GPa}, \rho_{20}{ }^{\circ} \mathrm{C}=7860 \mathrm{~kg} / \mathrm{m}^{3}, \nu_{20^{\circ} \mathrm{C}}=0.3$. According to [13], the influence of the temperature variation on the material density and Poisson's ratio of structural steel is very small, so the material density and Poisson's ratio under different temperatures can be replaced by the values at room temperature, $\rho_{T}=\rho_{20^{\circ} \mathrm{C}}$ and $\nu_{T}=\nu_{20^{\circ} \mathrm{C}}$; the influence of the temperature variation on the elastic modulus of the structural steel is very large, and the elastic modulus of the low carbon alloy steel under different temperatures can be calculated through the following equations:

$$
\begin{aligned}
E_{T}= & \varepsilon E_{20^{\circ} \mathrm{C}}, \\
\mathcal{E}= & -17.2 \times 10^{-12} T^{4}+11.8 \times 10^{-9} T^{3}-34.5 \\
& \times 10^{-7} T^{2}+15.9 \times 10^{-5} \mathrm{~T}+1,
\end{aligned}
$$

where $\varepsilon$ is the ratio coefficient of the structural steel elastic modulus under different temperatures; the temperature range is $T \in\left[0,600^{\circ} \mathrm{C}\right]$.

5.1. Convergence of the Finite Element Method. Assume that there is only one transverse open crack on the simply supported beam, and the relative position and depth of the crack are $x_{1} / L=0.5, a_{1} / h=0.5$; the temperature is $T=100^{\circ} \mathrm{C}$. When the $3 \mathrm{D}$ mesh sizes of the cracked beam are, respectively, $0.015 \mathrm{~m} \times 0.015 \mathrm{~m} \times 0.01 \mathrm{~m}, 0.001 \mathrm{~m} \times 0.001 \mathrm{~m} \times 0.001 \mathrm{~m}$, $0.0075 \mathrm{~m} \times 0.0075 \mathrm{~m} \times 0.005 \mathrm{~m}, 0.005 \mathrm{~m} \times 0.005 \mathrm{~m} \times 0.005 \mathrm{~m}$, $0.00375 \mathrm{~m} \times 0.00375 \mathrm{~m} \times 0.005 \mathrm{~m}, 0.0025 \mathrm{~m} \times 0.0025 \mathrm{~m} \times$ $0.0025 \mathrm{~m}, 0.002 \mathrm{~m} \times 0.002 \mathrm{~m} \times 0.002 \mathrm{~m}$, the natural frequencies of the cracked beam obtained by Patran and Nastran are shown in Figure 3.

As shown in Figure 3, the first three-order natural frequencies of the cracked beam obtained by the finite method are gradually converging to an exact value as the total number 


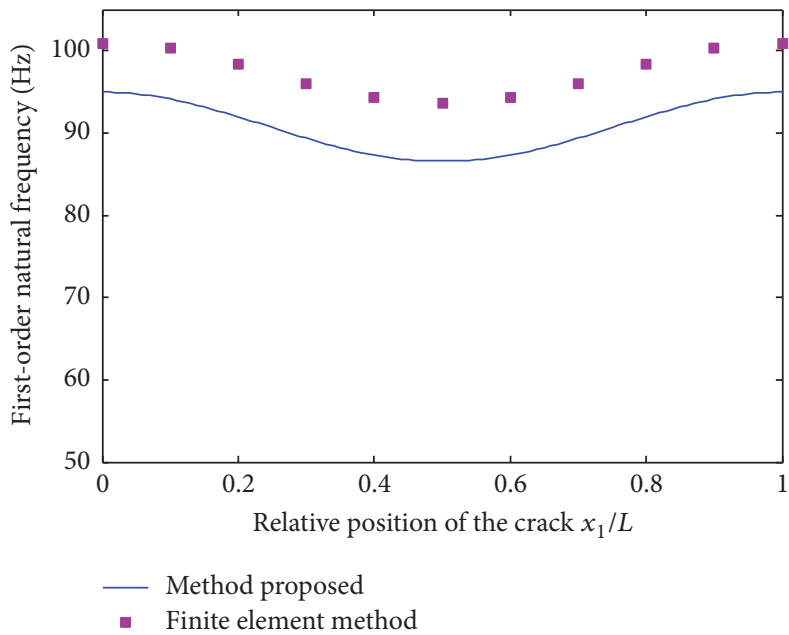

(a) First-order natural frequency

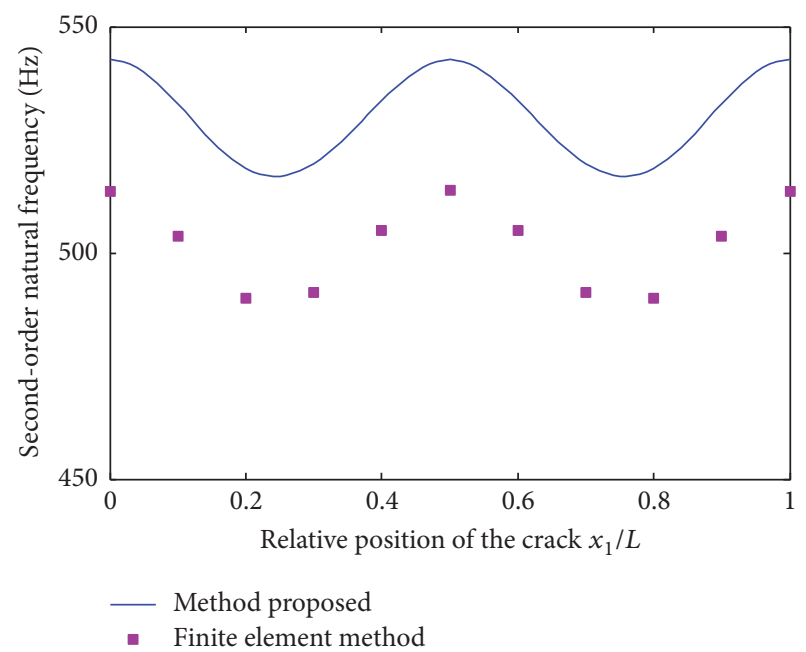

(b) Second-order natural frequency

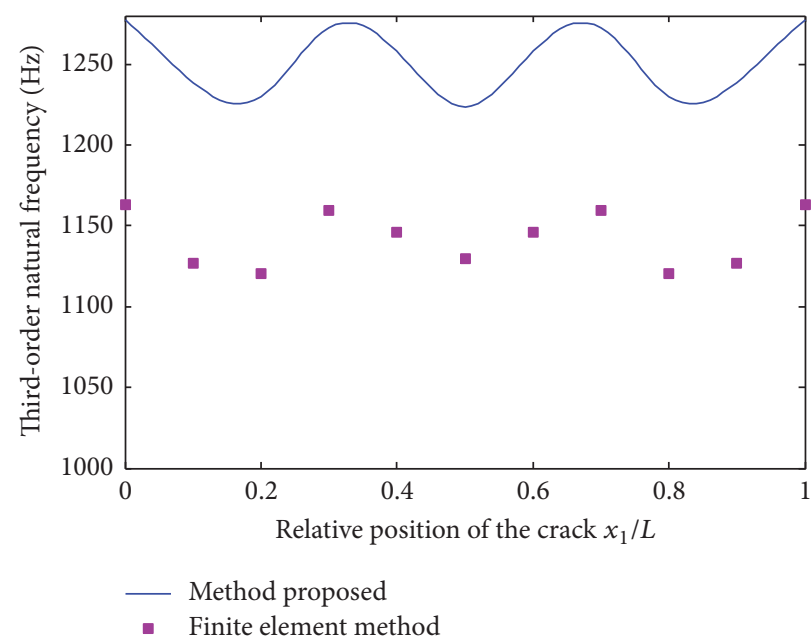

(c) Third-order natural frequency

FIgURE 4: Comparison of the first three-order natural frequencies obtained by two methods.

of elements increases. It can be proved that each of the order natural frequencies of the cracked beam obtained by Patran is convergent, and the finite element method can be used to verify the accuracy of the theoretical method proposed in this paper.

5.2. Comparison with Finite Element Results. Assume that there is only one transverse open crack on the simply supported beam, and the relative position and depth of the crack are $x_{1} / L \in[0,1], a_{1} / h=0.3$; the temperature is $T=$ $100^{\circ} \mathrm{C}$. The natural frequencies, calculated by the theoretical method proposed in this paper, are compared with the results obtained by the finite element method, as shown in Figure 4.

As shown in Figure 4, for the first three-order natural frequencies obtained by these two methods, the changing tendencies are the same as the relative position of the crack increases, and natural frequencies are symmetrical about the cross-section of the midpoint on the simply supported beam. For the first-order natural frequency, the effect of the crack on the stiffness of the beam gradually increases as the crack location is close to the midpoint, and the first-order natural frequency gradually decreases; when the crack is located at the midpoint, the maximum error of these two methods is $-7.52 \%$. For the second-order natural frequency, the midpoint of the simply supported beam is the second-order mode node, and the maximum error of these two methods is $5.54 \%$. For the third-order natural frequency, as shown in Figure 4(c), there are two nodes in the third-order mode, and the maximum error of these two methods is $9.01 \%$. There are three main reasons for the errors:

(1) The difference between the finite element model and the analytical model of the crack.

(2) The difference between the temperature load model in the finite element method and the axial load model in the analytical method.

(3) The natural errors of calculation method in the finite element model and the analytical model. 


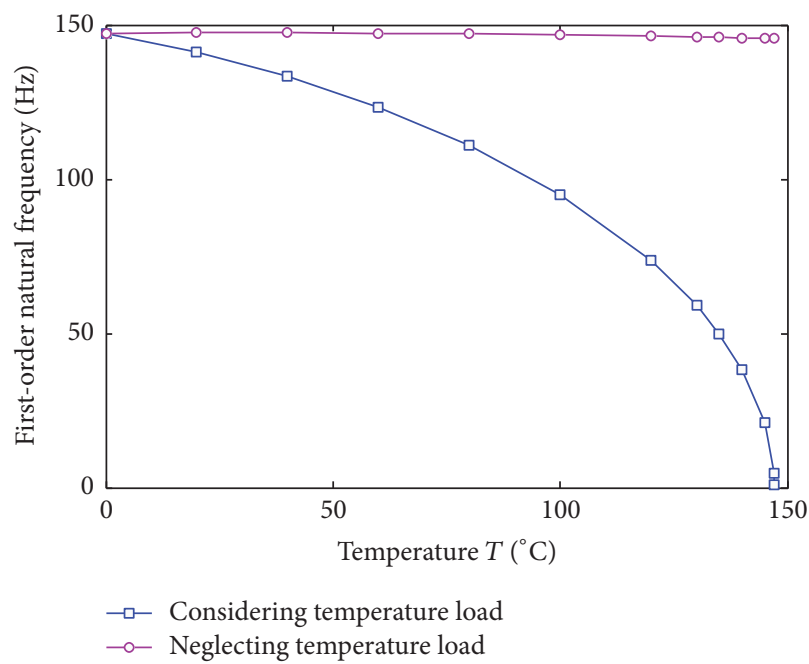

(a) First-order natural frequency

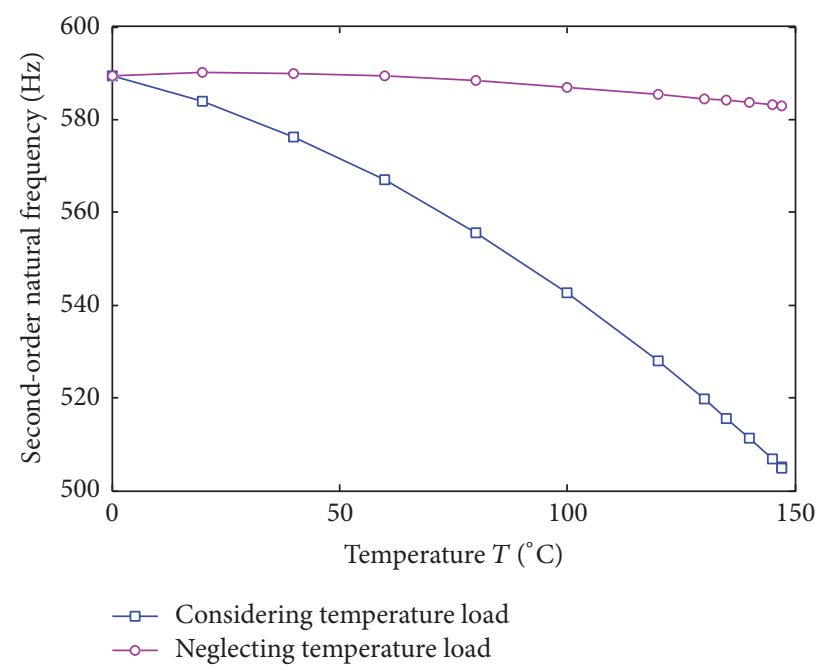

(b) Second-order natural frequency

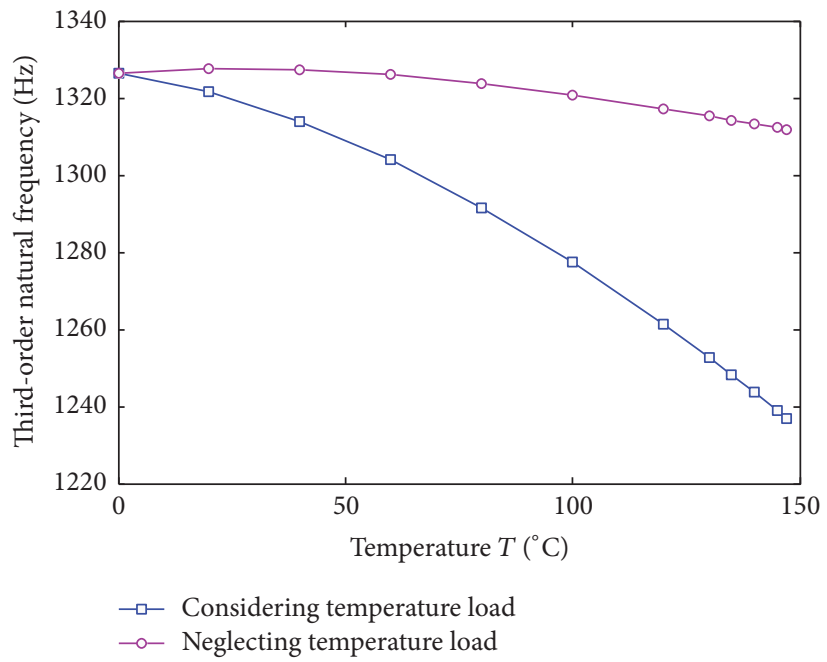

(c) Third-order natural frequency

FIGURE 5: Comparison of the first three-order natural frequencies in two cases.

The total error of the two methods is within a reasonable range, which is acceptable. In summary, the modal analysis method proposed in this paper has a high computational accuracy.

5.3. Temperature Load. Assume that there is no crack on the simply supported beam; the rise of temperature leads to the expansion of the simply supported beam, and the axial force is generated on the cross-section of the beam. When the first-order natural frequency of the simply supported beam is equal to zero $\left(\omega_{1, T_{\mathrm{cr}}}=0\right)$, the temperature at this time is defined as the critical temperature $T_{\mathrm{cr}}$. Considering the temperature load $N_{T}=E_{T} A \alpha_{s} T$ and neglecting the temperature load $N_{T}=0$, both kinds of situations are studied in the modal analysis, and the first-order natural frequencies are shown in Figure 5.

As shown in Figure 5, when the temperature load is considered and neglected, the first three-order natural frequencies of the simply supported steel beam differ greatly, so the axial force caused by the temperature rising cannot be ignored. When the temperature load is considered, the first three-order natural frequencies of the simply supported steel beam gradually decrease as the temperature increases, and the decreasing velocity of the natural frequency gradually increases as the temperature increases. When the first-order natural frequency is reduced to zero, the first-order instability mode of the simply supported beam is reached. As shown in Figure 5(a), when the temperature is equal to the critical temperature $T_{\mathrm{cr}}=147.1^{\circ} \mathrm{C}$, the first-order natural frequency of the beam decreases to zero.

5.4. Different Number of Cracks. Assume that there are three kinds of crack situations on the simply supported steel beam, which are as follows:

(1) There is only one transverse crack on the beam, and the geometric parameters of the crack are $x_{1} / L=0.5$, $a_{1} / h=0.1$. 


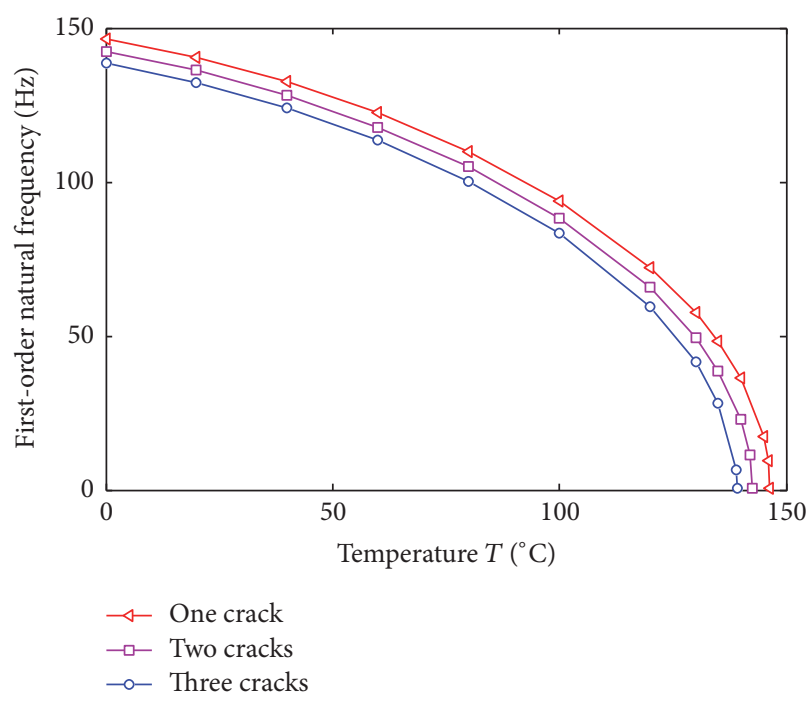

(a) First-order natural frequency

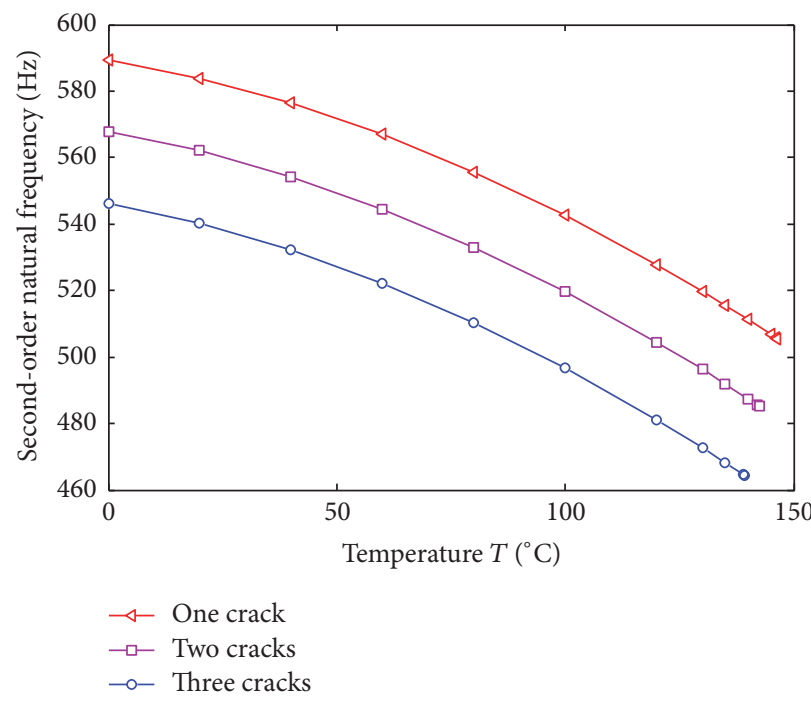

(b) Second-order natural frequency

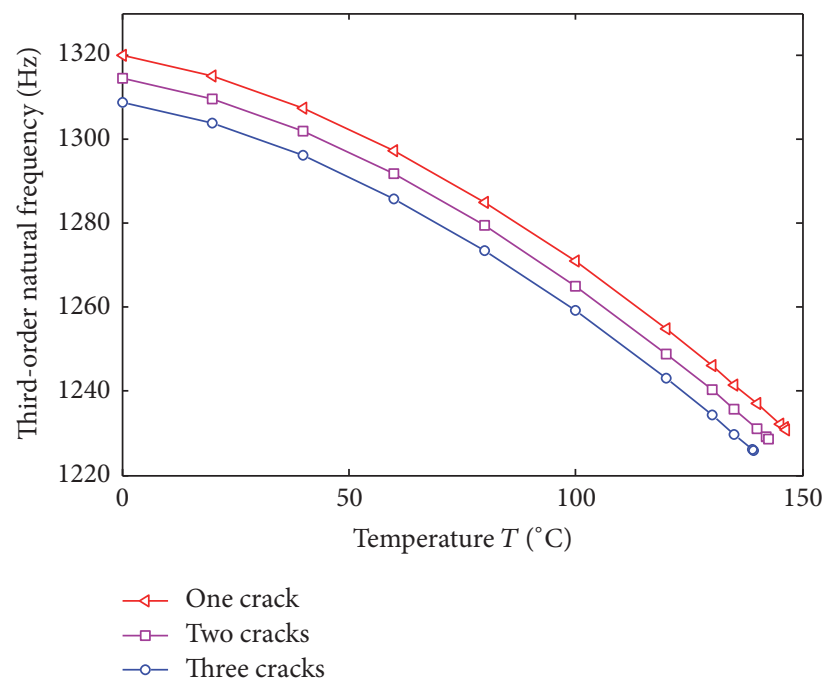

(c) Third-order natural frequency

FIGURE 6: First three-order natural frequencies of the beam with different number of cracks.

(2) There are two transverse cracks on the beam, and the geometric parameters of the cracks are $x_{1} / L=0.3$, $a_{1} / h=0.3 ; x_{2} / L=0.5, a_{2} / h=0.1$.

(3) There are three transverse cracks on the beam, and the geometric parameters of the cracks are $x_{1} / L=0.3$, $a_{1} / h=0.3 ; x_{2} / L=0.5, a_{2} / h=0.1 ; x_{3} / L=0.7, a_{3} / h=$ 0.3 .

If the temperature is in the range of critical temperature, considering the temperature load, the first three-order natural frequencies of the simply supported steel beam are shown in Figure 6.

For the simply supported beam with different number of cracks, the variations of the first three-order natural frequencies are shown in Figure 6. The first three-order natural frequencies of the simply supported cracked beam gradually decrease as the temperature increases, and the decreasing velocity gradually increases. When the temperature remains unchanged, the damage degree of the beam gradually increases as the number of cracks increases, and the first three-order natural frequencies of the beam gradually decrease. As shown in Figure 6(a), the critical temperature of the simply supported cracked beam also gradually decreases as the number of cracks increases.

5.5. Geometric Parameters of the Crack. Assume that there is only one transverse open crack on the simply supported steel beam, and the geometric parameters of the crack are $x_{1} / L \in[0,1], a_{1} / h \in[0,0.5]$. If the temperature $T=0^{\circ} \mathrm{C}$, the variations of the first three-order natural frequencies of the beam are shown in Figure 7.

For the beam with different geometric parameters of the crack, the variations of the first three-order natural 


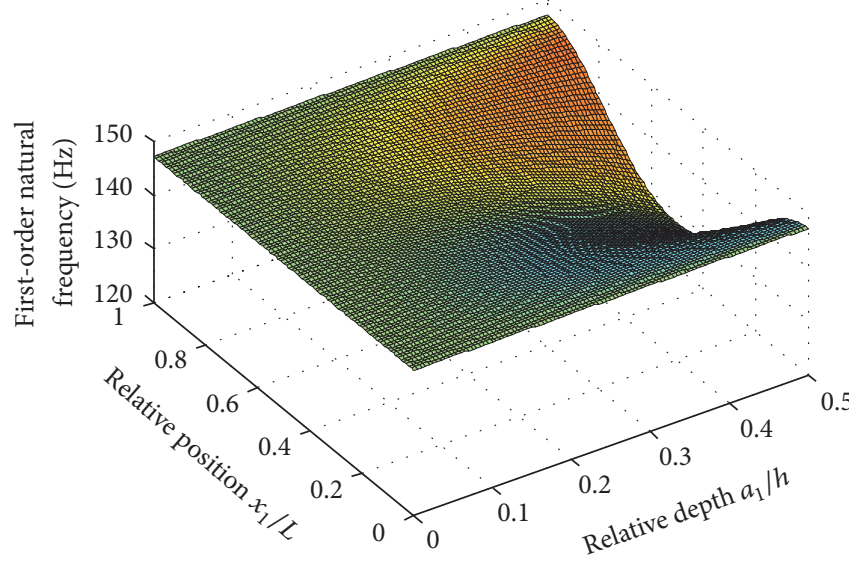

(a) First-order natural frequency

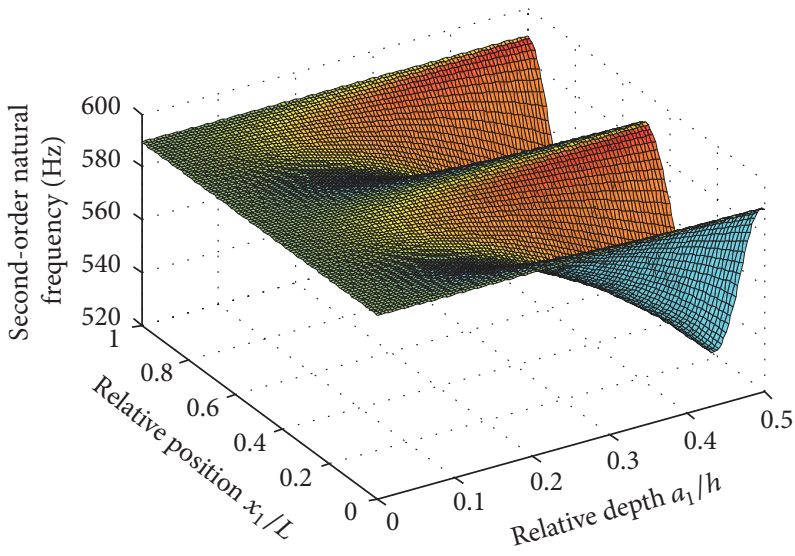

(b) Second-order natural frequency

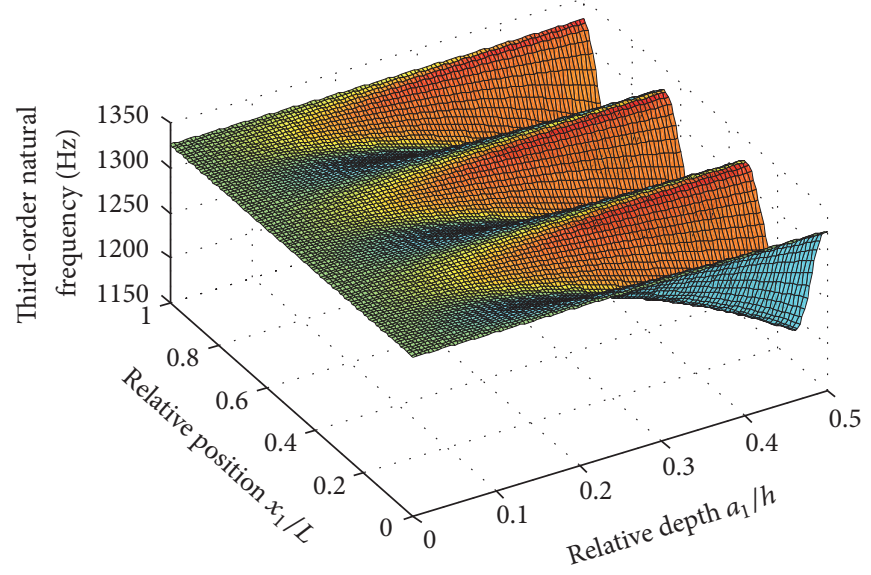

(c) Third-order natural frequency

FIGURE 7: First three-order natural frequencies of the beam with different geometric parameters of the crack.

frequencies are shown in Figure 7. The first three-order natural frequencies gradually decrease as the relative depth of the crack increases; when the crack is located at the nodes of each of the order modes of the simply supported beam, the influence of the relative depth of the crack on the corresponding order natural frequency is not very large. As shown in Figure 7(b), the second-order mode of the simply supported beam has only one node; as shown in Figure 7(c), the third-order mode of the simply supported beam has two nodes.

5.6. Critical Temperature. Assume that there are three kinds of cracks cases on the simply supported steel beam, which are as follows:

(1) There is only one transverse crack on the beam, and the geometric parameters of the crack are $x_{1} / L=0.5$, $a_{1} / h \in[0,0.5]$.

(2) There are two transverse cracks on the beam, and the geometric parameters of the cracks are $x_{2} / L=0.3$, $a_{2} / h=0.3 ; x_{1} / L=0.5, a_{1} / h \in[0,0.5]$.

(3) There are three transverse cracks on the beam, and the geometric parameters of the cracks are $x_{2} / L=0.3$,

$$
\begin{aligned}
& a_{2} / h=0.3 ; x_{1} / L=0.5, a_{1} / h \in[0,0.5] ; x_{3} / L=0.7, \\
& a_{3} / h=0.3 .
\end{aligned}
$$

For the simply supported steel beam with different geometric parameters of cracks, the variations of the critical temperatures are shown in Figure 8.

As shown in Figure 8, when the number of the cracks remains unchanged, the critical temperature of the simply supported steel beam gradually decreases as the relative depth of the crack increases, and the decreasing velocity gradually increases. When the relative depths of cracks remain unchanged, the critical temperature of the beam gradually decreases as the number of the cracks increases (the damage degree of the cracks on the simply supported beam gradually increases).

\section{Conclusions}

Under different temperatures, this paper proposes a new analytical method to conduct the modal analysis of a special simply supported steel beam with multiple cracks, which is that the left and right ends are simply supported and cannot move. The temperature rising causes the thermal expansion 


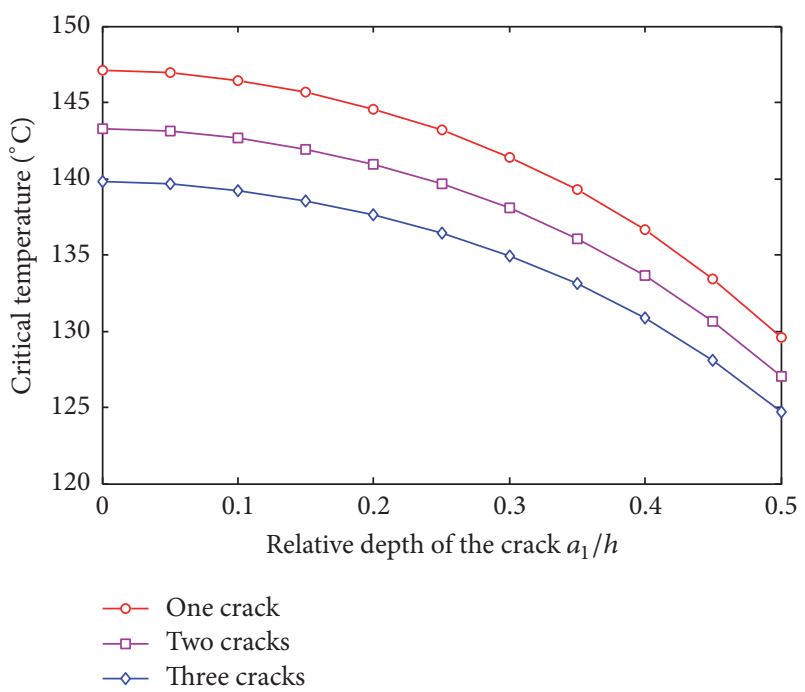

FIgURE 8: Critical temperatures of the beam with different geometric parameters of cracks.

of the beam, and the axial force is generated on the crosssection of the simply supported beam. In the modal analysis of the simply supported steel with multiple cracks, the variation of the mechanical properties and the temperature load caused by the temperature rising are considered, and the torsion springs without mass are used to replace the transverse cracks, then the transfer matrix method is used to calculate the natural frequencies of the cracked simply supported steel beam.

The proposed method is verified by the finite element method, and the comparison shows that the proposed method has a very accurate computation. Besides, compared with neglecting the temperature load, considering the temperature load is more in line with the actual situation of the engineering.

\section{Conflicts of Interest}

The authors declare that they have no conflicts of interest.

\section{Acknowledgments}

This work is supported by the National Natural Science Foundation of China (no. 51605202) and the Natural Science Foundation of Jiangsu Province (no. BK20160550).

\section{References}

[1] L. M. R. Mesquita, P. A. G. Piloto, M. A. P. Vaz, and P. M. M. Vila Real, "Experimental and numerical research on the critical temperature of laterally unrestrained steel I beams," Journal of Constructional Steel Research, vol. 61, no. 10, pp. 1435-1446, 2005.

[2] Z.-F. Huang and K.-H. Tan, "Rankine approach for fire resistance of axially-and-flexurally restrained steel columns," Journal of Constructional Steel Research, vol. 59, no. 12, pp. 1553-1571, 2003.
[3] Y. Pi L and M. Bradford A, "Interval thermoelastic response of elastically restrained steel beams," Procedia Engineering, vol. 14, pp. 2117-2123, 2011.

[4] A. Heidarpour and M. A. Bradford, "Generic nonlinear modelling of restrained steel beams at elevated temperatures," Engineering Structures, vol. 31, no. 11, pp. 2787-2796, 2009.

[5] K.-H. Tan and Z.-F. Huang, "Structural responses of axially restrained steel beams with semirigid moment connection in fire," Journal of Structural Engineering, vol. 131, no. 4, pp. 541551, 2005.

[6] V. K. R. Kodur and M. M. S. Dwaikat, "Response of steel beamcolumns exposed to fire," Engineering Structures, vol. 31, no. 2, pp. 369-379, 2009.

[7] A. N. Ndoukouo, A. Nubissie, and P. Woafo, "On the dynamics of fire-exposed steel beam under mechanical load," Journal of Constructional Steel Research, vol. 67, no. 12, pp. 1864-1871, 2011.

[8] A. Mahi, E. A. Adda Bedia, A. Tounsi, and I. Mechab, "An analytical method for temperature-dependent free vibration analysis of functionally graded beams with general boundary conditions," Composite Structures, vol. 92, no. 8, pp. 1877-1887, 2010.

[9] Z. Wang, L. Bing, and Y. Han, "Free vibration frequency variation analysis of a cracked aluminum alloy beam under high temperatures," Journal of Harbin Engineering University, vol. 33, no. 3, pp. 320-324, 2012.

[10] Y. Ma and G. Chen, "Modal analysis of a rectangular variable cross-section beam with multiple cracks under different temperatures," Journal of Vibroengineering, vol. 18, no. 5, pp. 30783088, 2016.

[11] D. Karličić, D. Jovanović, P. Kozić, and M. Cajić, “Thermal and magnetic effects on the vibration of a cracked nanobeam embedded in an elastic medium," Journal of Mechanics of Materials and Structures, vol. 10, no. 1, pp. 43-62, 2015.

[12] A. Dimarogonas D and S. Paipetis A, "Analytical Methods in Rotor Dynamics," in Mechanisms \& Machine Science, vol. 9, Springer, 2nd edition, 1983.

[13] ASCE, ASCE manuals and reports on engineering practice, Publishing Books with Asce.

[14] L. Meirovitch, Elements of vibration analysis, McGraw-Hill international editions, 1986.

[15] B. Binici, "Vibration of beams with multiple open cracks subjected to axial force," Journal of Sound and Vibration, vol. 287, no. 1-2, pp. 277-295, 2005.

[16] A. J. Dentsoras and A. D. Dimarogonas, "Resonance controlled fatigue crack propagation in a beam under longitudinal vibrations," International Journal of Fracture, vol. 23, no. 1, pp. 15-22, 1983. 


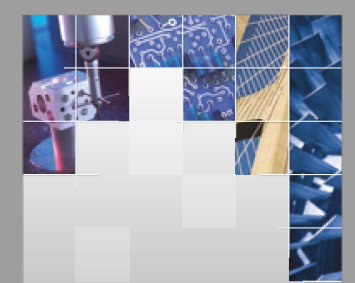

\section{Enfincering}
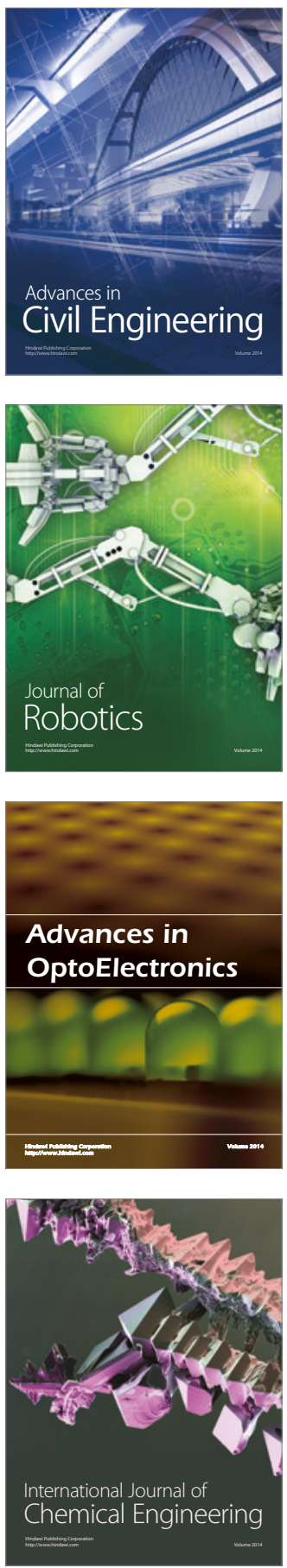

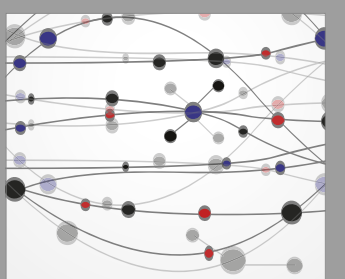

The Scientific World Journal

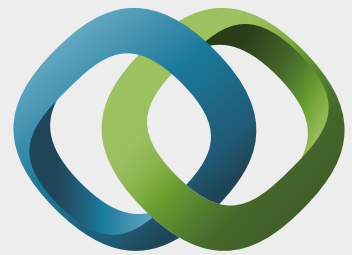

\section{Hindawi}

Submit your manuscripts at

https://www.hindawi.com
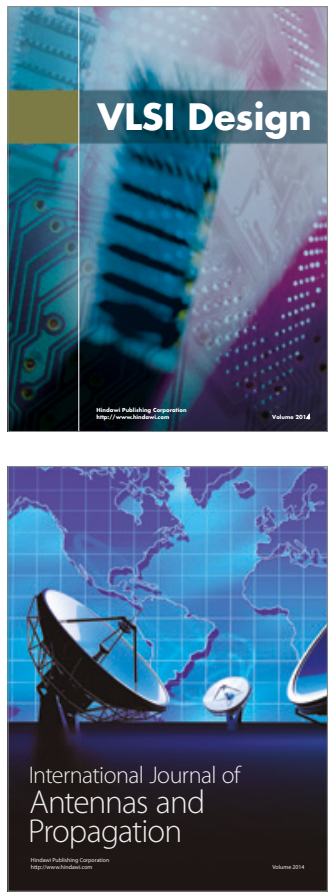

\section{Rotating}

Machinery
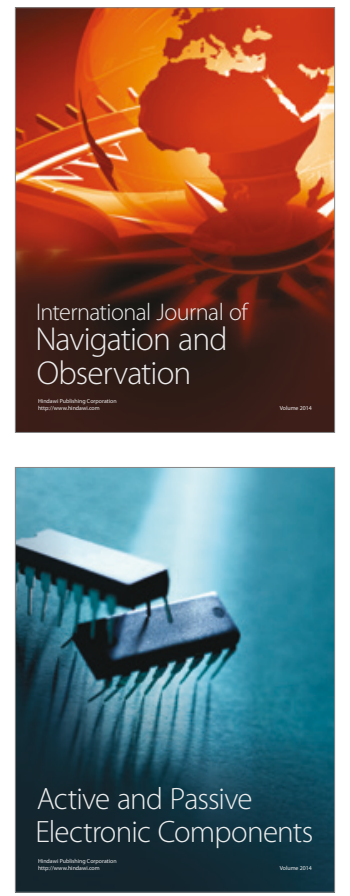
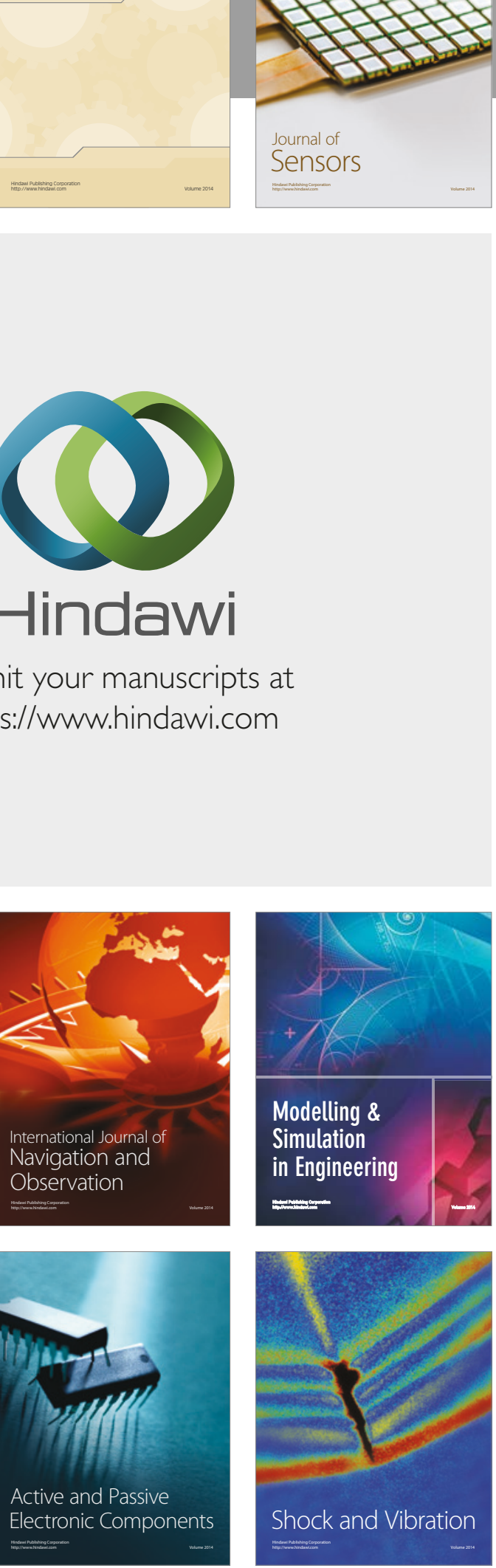
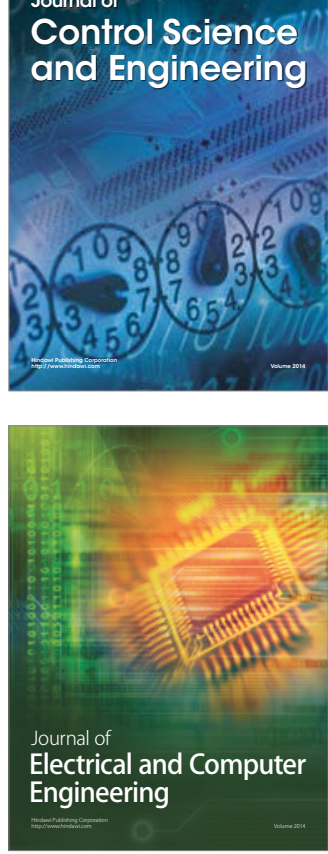

Distributed

Journal of

Control Science

and Engineering
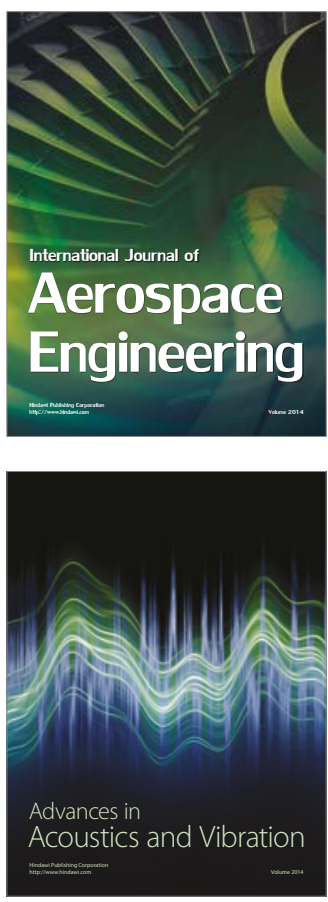

Sensor Networks 